\title{
Dynamics of a Key Conformational Transition in the Mechanism of Peroxiredoxin
}

\section{Sulfinylation}

by

Alexandre Kriznik ${ }^{1,2}$, Marouane Libiad ${ }^{3}$, Hélène Le Cordier $^{1}$, Samia Boukhenouna ${ }^{1}$, Michel B Toledano $^{3}$ \& Sophie Rahuel-Clermont ${ }^{1,2 *}$

${ }^{1}$ IMoPA, Université de Lorraine, CNRS, Biopole, Campus Biologie Santé, F-54000 Nancy, France

2 UMS2008 IBSLor, Biophysics and Structural Biology core facility, Université de Lorraine, CNRS, INSERM, Biopole, Campus Biologie Santé, F-54000 Nancy, France

${ }^{3}$ Institute for Integrative Biology of the Cell (I2BC), UMR9198, CNRS, CEA-Saclay, Université Paris-Saclay, iBiTecS/SBIGEM, Laboratoire Stress oxydant et Cancer, Bat 142, F-91198 Gif-surYvette Cedex, France

*E-mail: sophie.rahuel@univ-lorraine.fr 


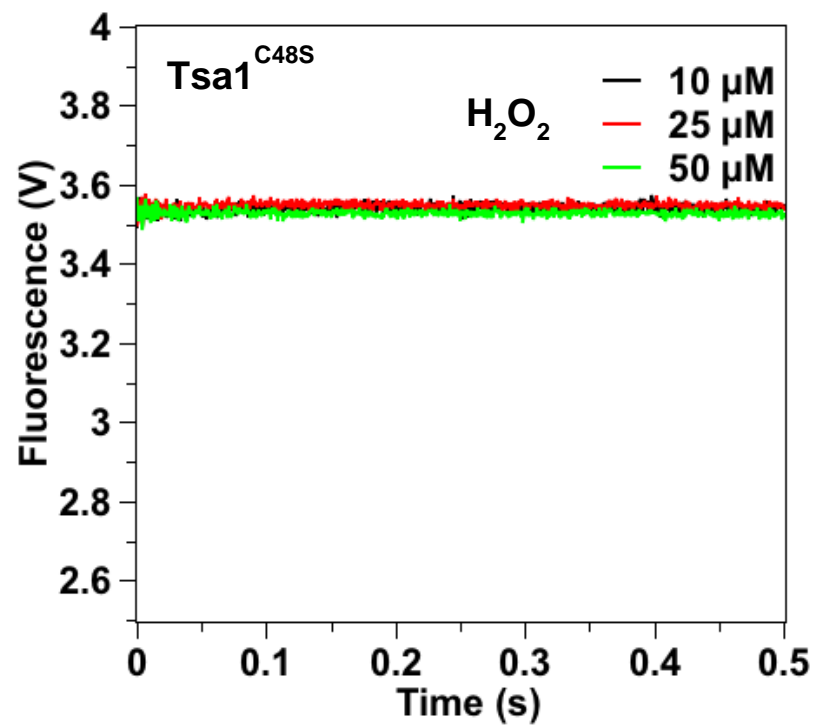

Figure S1. Pre-steady state kinetics for the reaction of Tsa1 ${ }^{\mathrm{C} 485}(5 \mu \mathrm{M})$ with increasing $\mathrm{H}_{2} \mathrm{O}_{2}(10,25,50$ $\mu \mathrm{M})$ monitored by Trp fluorescence as in Fig. $2 \mathrm{~b}$.

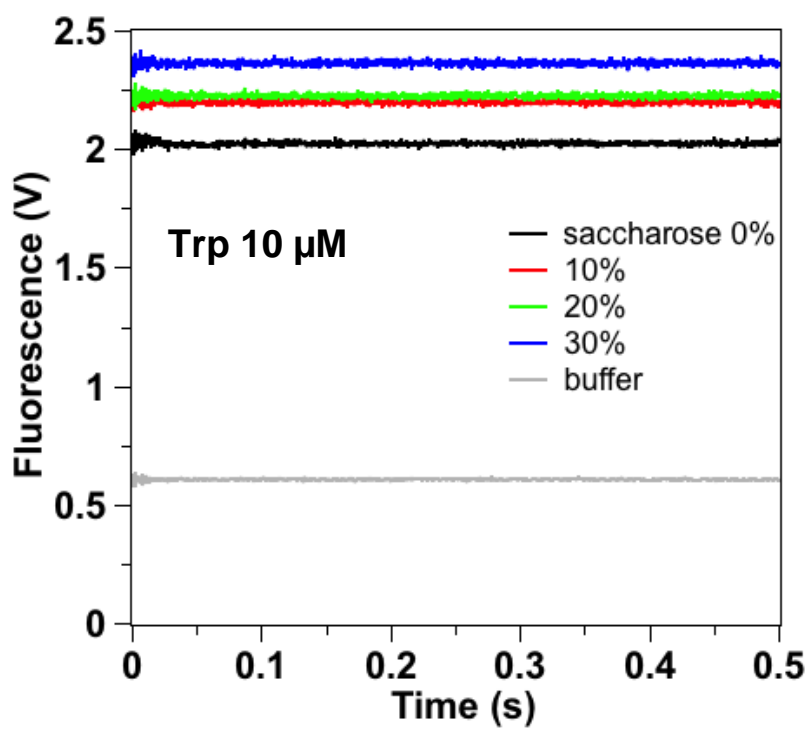

Figure S2. Test of stop flow mixer efficiency in viscous solutions, based on the effect of saccharose $(0 \%$ black, $10 \%$ red, $20 \%$ green and $30 \%$ blue) on Trp amino-acid fluorescence (10 $\mu \mathrm{M})$ monitored as in Fig. $2 b$. 

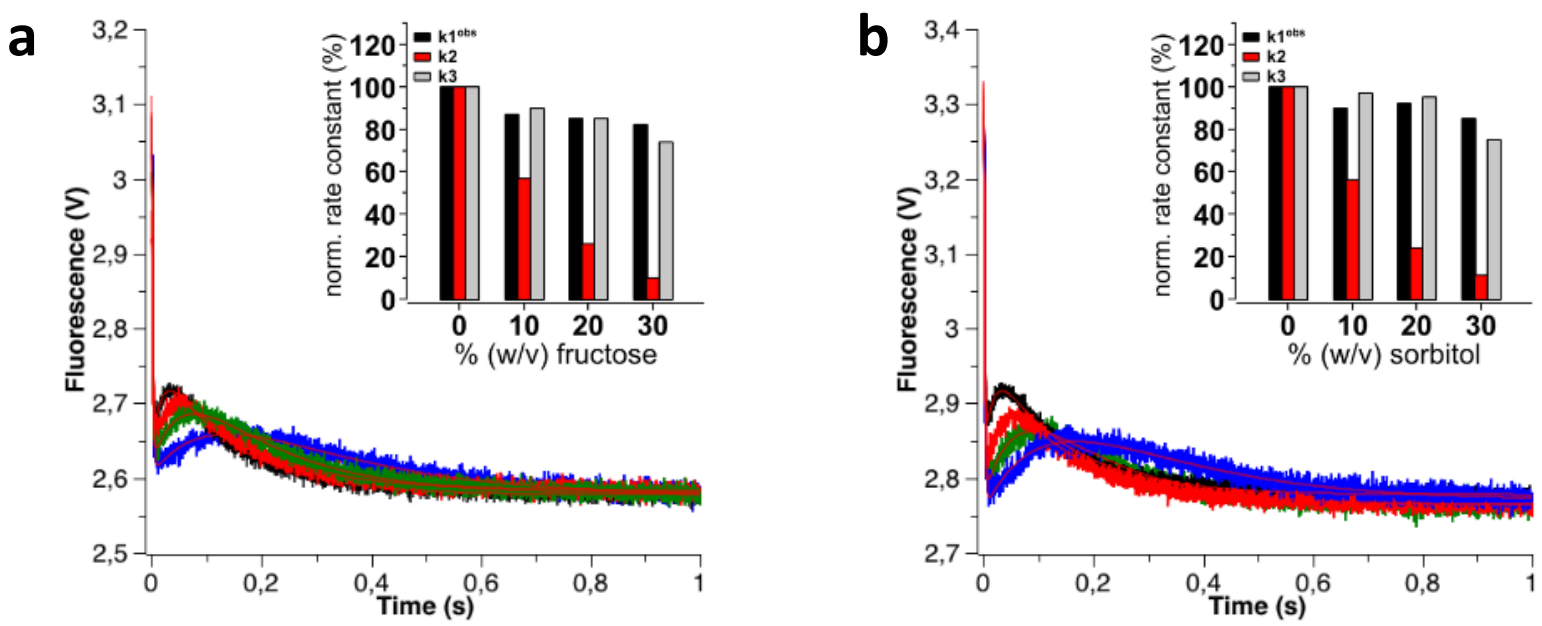

Figure S3. Effect of viscogens fructose (a) and sorbitol (b) (0\% black, $10 \%$ red, $20 \%$ green and 30\% blue) on the reaction of Tsa1 $(5 \mu \mathrm{M})$ with $\mathrm{H}_{2} \mathrm{O}_{2}(10 \mu \mathrm{M})$ monitored as in Fig. 2, fitted against a 3exponential equation (red lines). Insets, effect of viscogen concentration on rate constants $k 1^{\text {obs }}, k 2$ and $\mathrm{k} 3$ normalized to $0 \%$ viscogen.

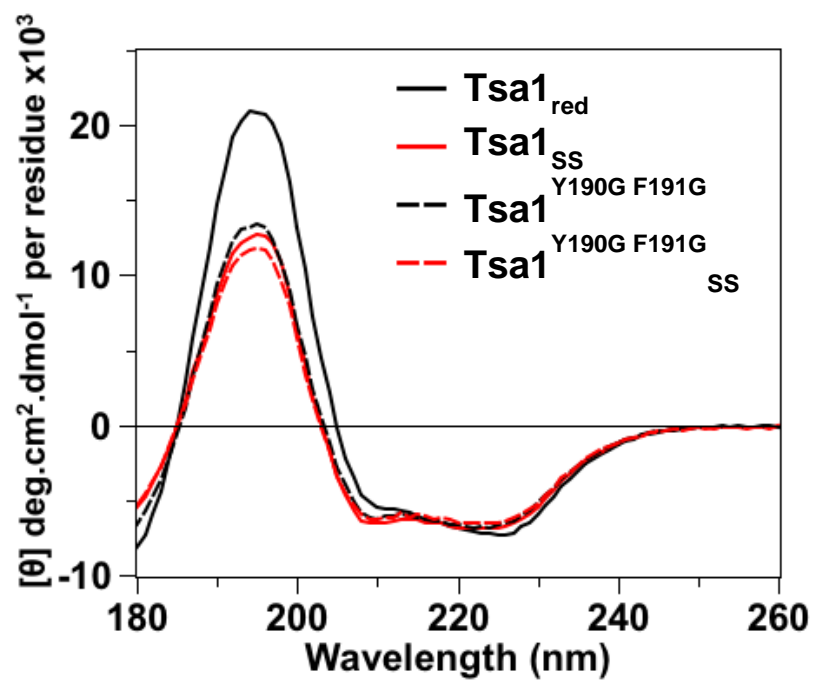

Figure S4. Far-UV CD spectra of $5 \mu \mathrm{M}$ wild-type Tsa1 (plain) and Tsa1 $1^{\mathrm{Y190G} F 191 G}$ (dash line) under the reduced (black) and disulfide (red) forms. Measurements were performed in a $0.01 \mathrm{~cm}$ flat cell in phosphate $(10 \mathrm{mM}) \mathrm{NaF}(100 \mathrm{mM})$ buffer $\mathrm{pH} 7$ and are the average of three records. 


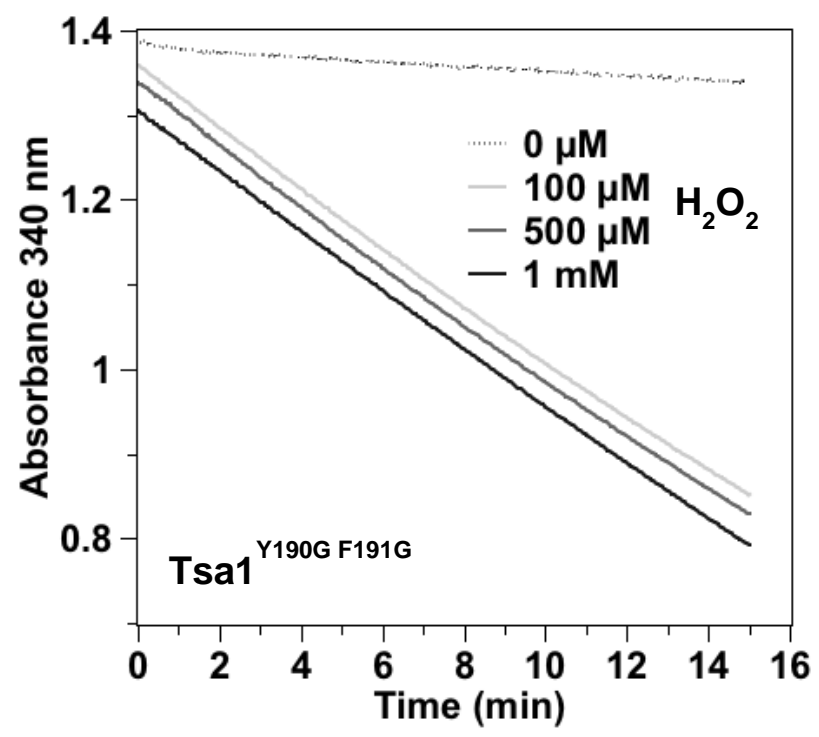

Figure S5. Steady state kinetics for the determination of the hyperoxidation sensitivity of Tsa1 $1^{\text {Y190G F191G }}$ with $\mathrm{H}_{2} \mathrm{O}_{2}$ monitored by consumption of NADPH $(200 \mu \mathrm{M})$ at $340 \mathrm{~nm}$ in the presence $E$. coli thioredoxin reductase $(0.25 \mu \mathrm{M}), E$. coli Trx1 $(5 \mu \mathrm{M})$, Tsa1 $(1 \mu \mathrm{M})$ and variable amounts of $\mathrm{H}_{2} \mathrm{O}_{2}$ (from $100 \mu \mathrm{M}$ to 1 $\mathrm{mM}$ ) in TK buffer. The time courses have been shifted on the $y$-axis for clarity.

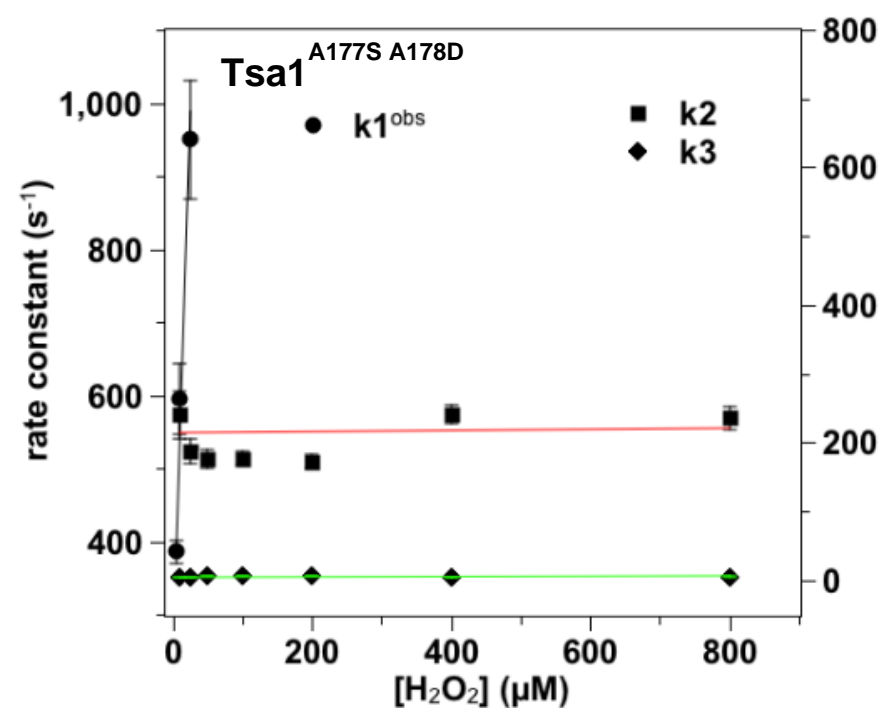

Figure S6. Second order plots and linear fits of the observed rate constants $\mathrm{k} 1^{\text {obs }}$ (circles, black line), k2 (squares, red line) and k3 (diamond, green line) for Tsa1 ${ }^{\mathrm{A} 1775 \mathrm{A178D}}$ reaction kinetics with $\mathrm{H}_{2} \mathrm{O}_{2}$. 


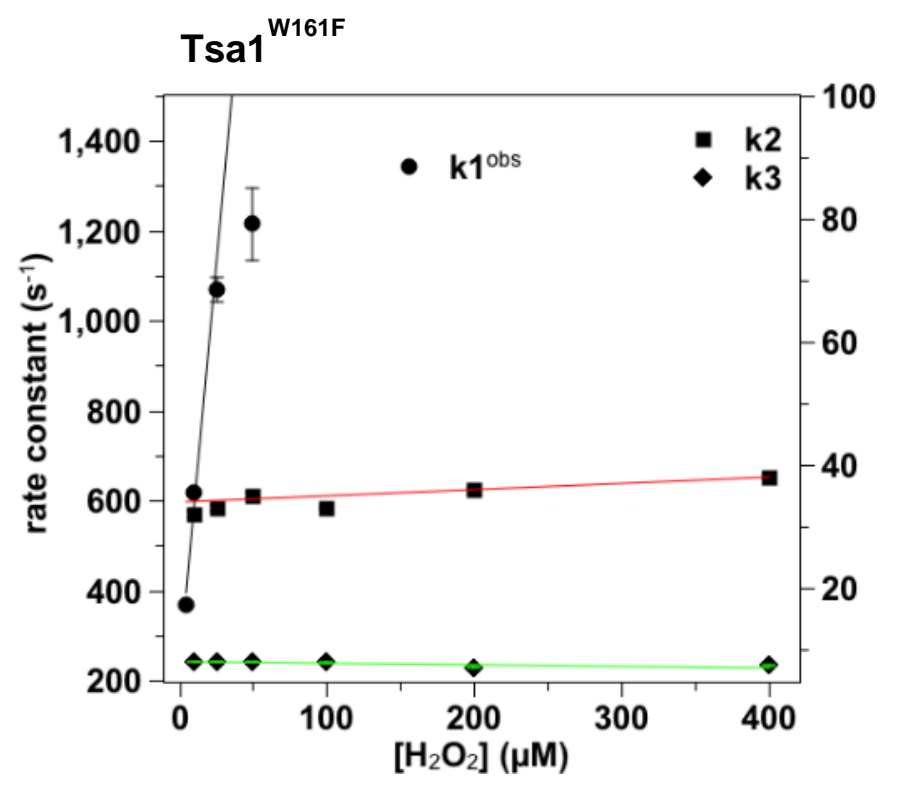

Figure S7. Second order plots and linear fits of the observed rate constants $\mathrm{k} 1^{\text {obs }}$ (circles, black line), k2 (squares, red line) and $\mathrm{k} 3$ (diamond, green line) for Tsa $1^{\text {W161F }}$ reaction kinetics with $\mathrm{H}_{2} \mathrm{O}_{2}$.

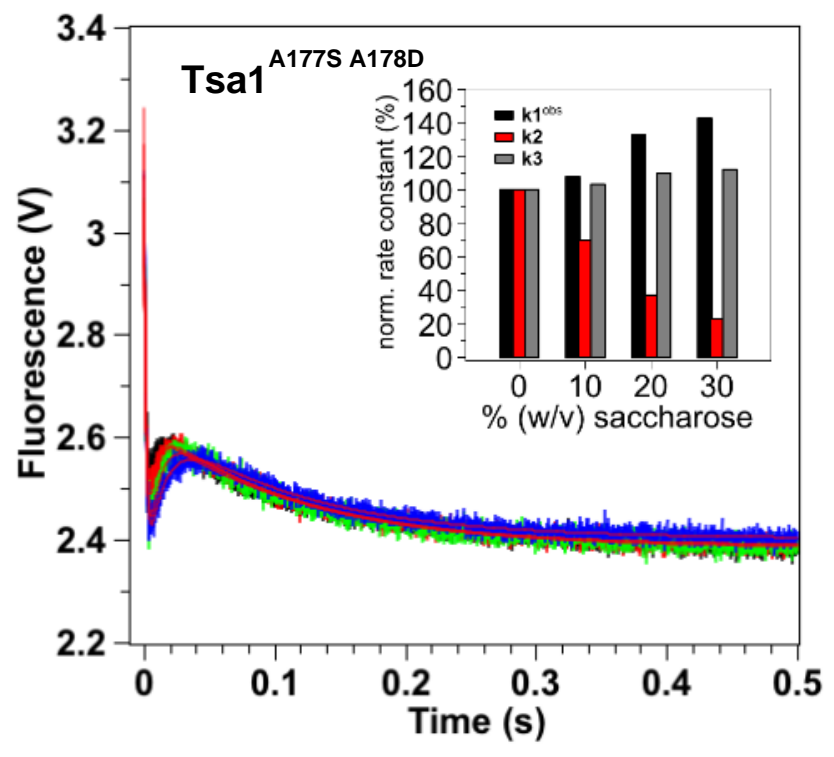

Figure S8. Effect of saccharose (0\% black, $10 \%$ red, $20 \%$ green and $30 \%$ blue) on the reaction of Tsa1 ${ }^{\mathrm{A} 1775 \mathrm{~A} 178 \mathrm{D}}(5 \mu \mathrm{M})$ with $\mathrm{H}_{2} \mathrm{O}_{2}(10 \mu \mathrm{M})$ monitored as in Fig. 2b, fitted against a 3-exponential equation (red line). Inset, effect of saccharose concentration on rate constants k1 ${ }^{\text {obs }}$, k2 and k3 normalized to $0 \%$ saccharose. 


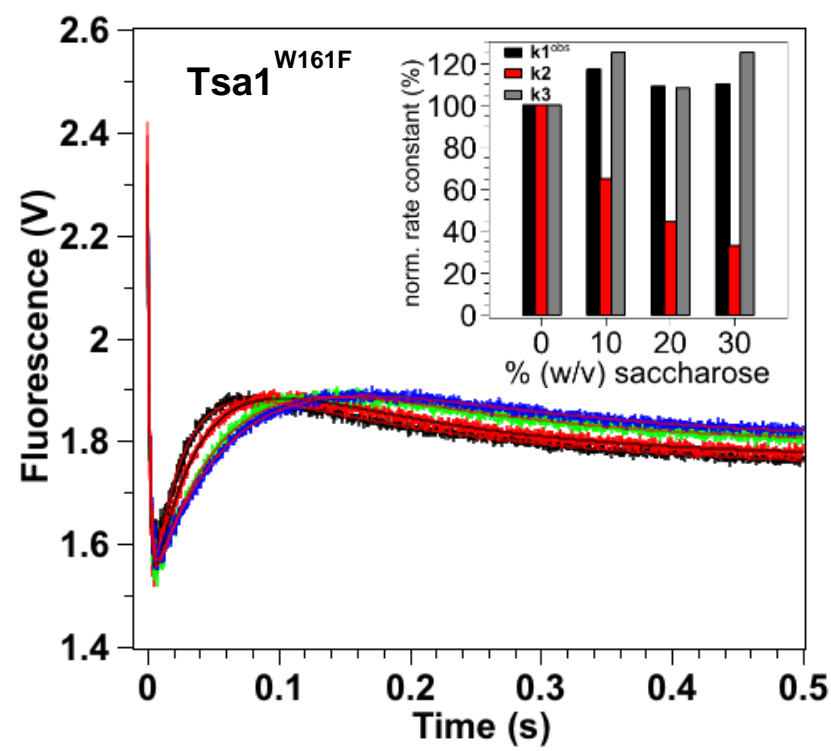

Figure S9. Effect of saccharose (0\% black, $10 \%$ red, $20 \%$ green and $30 \%$ blue) on the reaction of Tsa1 ${ }^{\text {W161F }}(5 \mu \mathrm{M})$ with $\mathrm{H}_{2} \mathrm{O}_{2}(10 \mu \mathrm{M})$ monitored as in Fig. $2 \mathrm{~b}$, fitted against a 3-exponential equation (red or black line). Inset, effect of saccharose concentration on rate constants $k 1^{\text {obs }}, k 2$ and $k 3$ normalized to $0 \%$ saccharose.

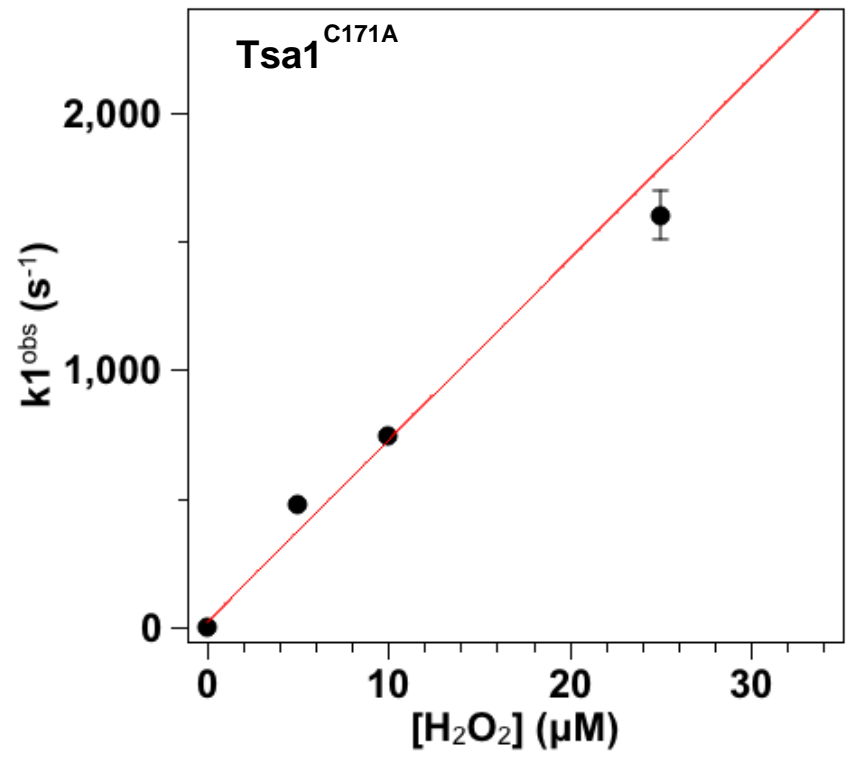

Figure S10. Second order plot and linear fit of the observed rate constants $\mathrm{k}^{\text {obs }}$ vs $\mathrm{H}_{2} \mathrm{O}_{2}$ concentration, for the reaction kinetics of Tsa $1^{\mathrm{C} 171 \mathrm{~A}}$ with $\mathrm{H}_{2} \mathrm{O}_{2}$. 


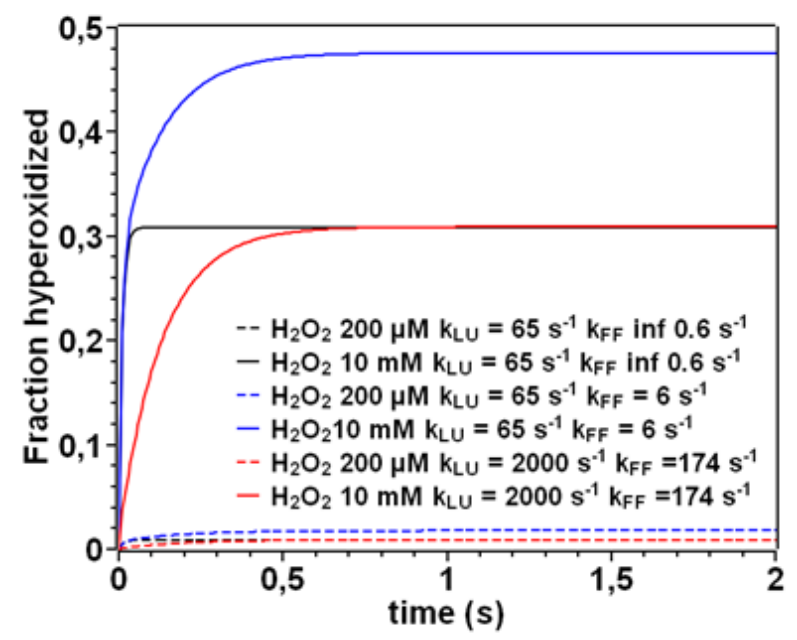

Figure S11. Simulation of the kinetics of formation of $\mathrm{Tsa}_{\mathrm{sO2}}$. Simulations were performed based on the model from Figure $6 \mathrm{~b}$, using the fitted rate constants values $\mathrm{k}_{\mathrm{sOH}}$ and $\mathrm{k}_{\mathrm{sO} 2}$ reported in Table 1 and the indicated values for $\mathrm{k}_{\mathrm{LU}}, \mathrm{k}_{\mathrm{FF}}$ and $\mathrm{H}_{2} \mathrm{O}_{2}$ concentrations. Using fluorescence intensity factors of 62 and $124 \%$ for Tsa1 ${ }_{\text {ss }}$ and Tsa $1_{\text {so2 }}$ respectively (Figure $2 \mathrm{a}$ ), the fraction of Tsa1 in each state at completion of the reaction was estimated from Figure 6a data. At $\mathrm{H}_{2} \mathrm{O}_{2}$ concentrations of $200 \mu \mathrm{M}$ and $10 \mathrm{mM}$, Tsa $1_{\text {so2 }}$ contributes to $1 \%$ and $30 \%$ of the total, and Tsa $1_{\text {ss }}$ the remainder up to $100 \%$ (black lines). Fixing $k_{L U}$ at the fitted value of $65 \mathrm{~s}^{-1}$ and setting $\mathrm{k}_{\mathrm{FF}}$ to values higher than $0.6 \mathrm{~s}^{-1}$ increased the hyperoxidized fraction to values incompatible with experimental observations. For instance, with $\mathrm{k}_{\mathrm{FF}}=$ $6 \mathrm{~s}^{-1} \mathrm{Tsa}_{\mathrm{so} 2}$ reaches 2 and $48 \%$ at $200 \mu \mathrm{M}$ and $10 \mathrm{mM} \mathrm{H}_{2} \mathrm{O}_{2}$, respectively (blue lines). This supports that $\mathrm{k}_{\mathrm{FF}} \ll<\mathrm{k}_{\mathrm{Lu}}$.

To simulate the $\mathrm{Tsa} 1^{\mathrm{FF}}-\mathrm{SOH} \leftrightarrows \mathrm{Tsa} 1^{\mathrm{LU}}-\mathrm{SOH}$ in rapid equilibrium, $\mathrm{k}_{\mathrm{LU}}$ was set at $2000 \mathrm{~s}^{-1}$, in which case fractions of $\mathrm{Tsa}_{\mathrm{SO} 2}$ consistent with observation were obtained for $\mathrm{k}_{\mathrm{FF}}=174^{\mathrm{s}-1}$ (red lines). However in this case the FF to LU conformational event would be too fast to be observed in fluorescence, and the rate constant of Tsa $1_{\mathrm{sO} 2}$ formation would be of $\sim 5 \mathrm{~s}^{-1}$, i.e. , mostly controlled by kss. 

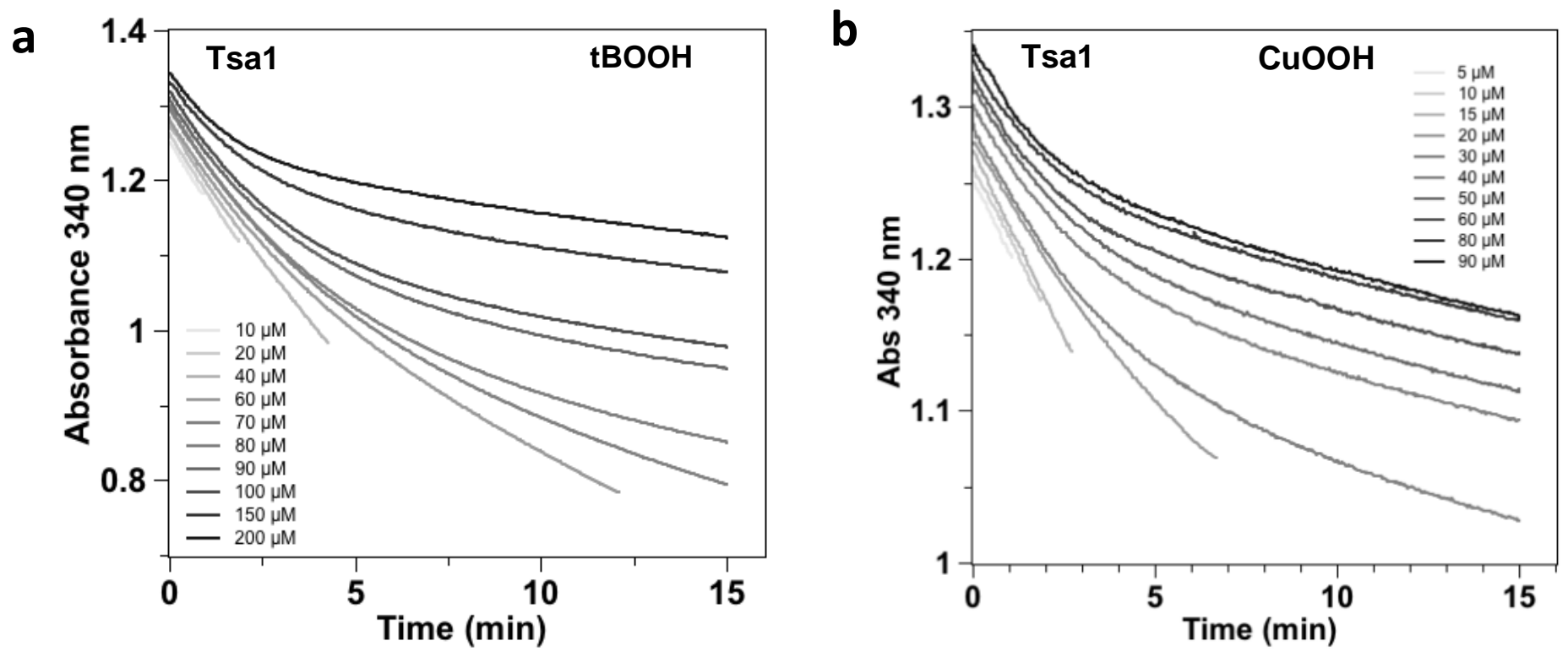

Figure S12. Steady state kinetics for the determination of hyperoxidation sensitivity of Tsa1 with tBOOH monitored by consumption of NADPH $(200 \mu \mathrm{M})$ at $340 \mathrm{~nm}$ in the presence thioredoxin reductase $(0.25 \mu \mathrm{M}), \operatorname{Trx} 1(5 \mu \mathrm{M})$, Tsa1 $(1 \mu \mathrm{M})$ and variable amounts of (a) tBOOH (from 10 to $200 \mu \mathrm{M}$ as indicated), and (b) $\mathrm{CuOOH}$ (as indicated). The time courses have been shifted on the $y$-axis for clarity. 

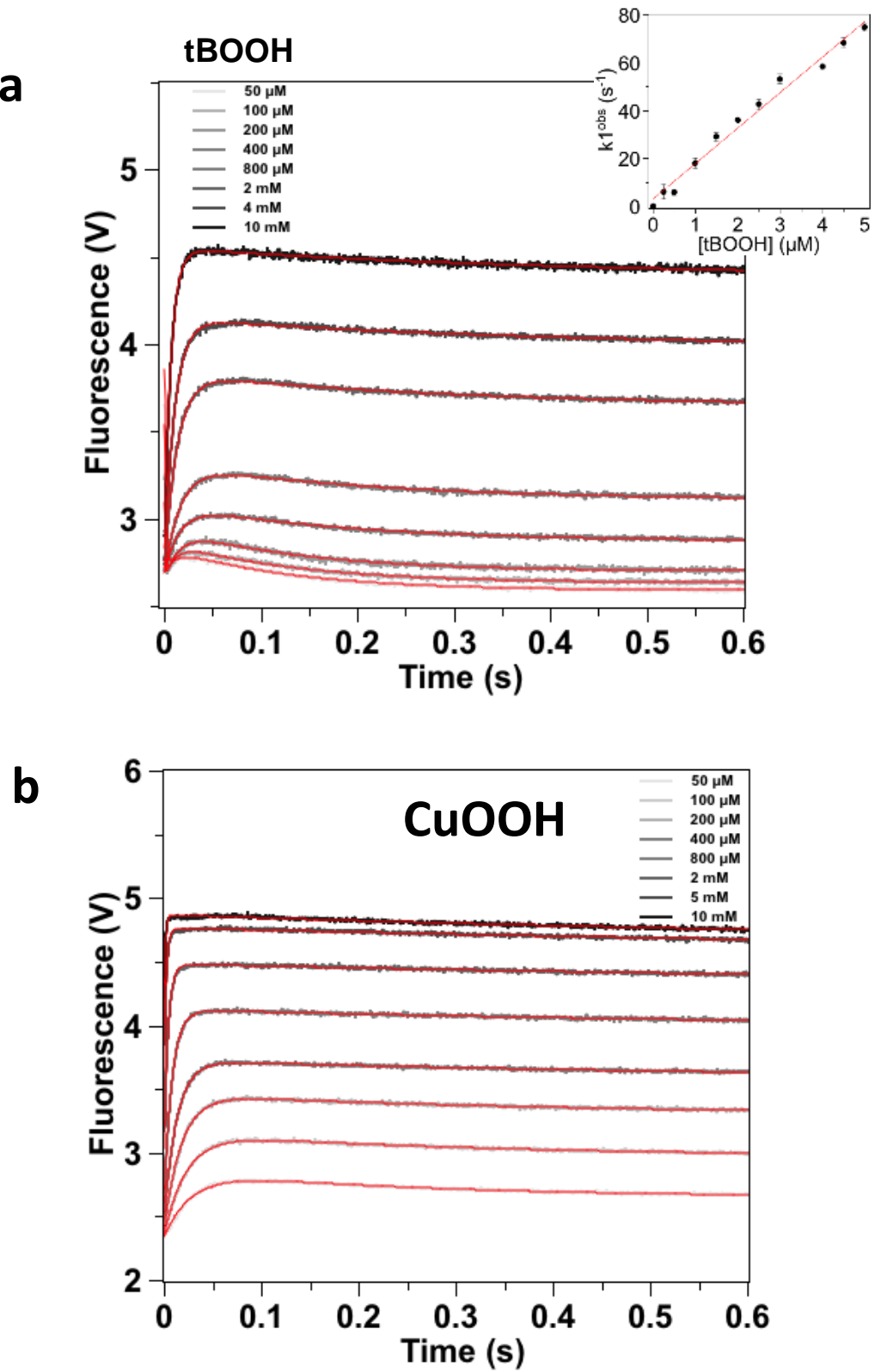

Figure S13. a. Pre-steady state kinetics for the reaction of Tsa1 $(5 \mu \mathrm{M})$ with $\mathrm{tBOOH}$ (as indicated) monitored as in Fig. 2B, fitted against a multiexponential equation (red line). Inset, precise determination of $\mathrm{k} 1$ by second order plot and linear fit of the rate constants $\mathrm{k} 1^{\text {obs }}$ obtained from kinetics measured for the reaction of Tsa1 $(0.5 \mu \mathrm{M})$ with low tBOOH concentrations (from 0.5 to $5 \mu \mathrm{M}$ ). b. Pre-steady state kinetics for the reaction of Tsa1 $(5 \mu \mathrm{M})$ with $\mathrm{CuOOH}$ (as indicated) monitored as in Fig. 2B, fitted against a multiexponential equation (red line). 

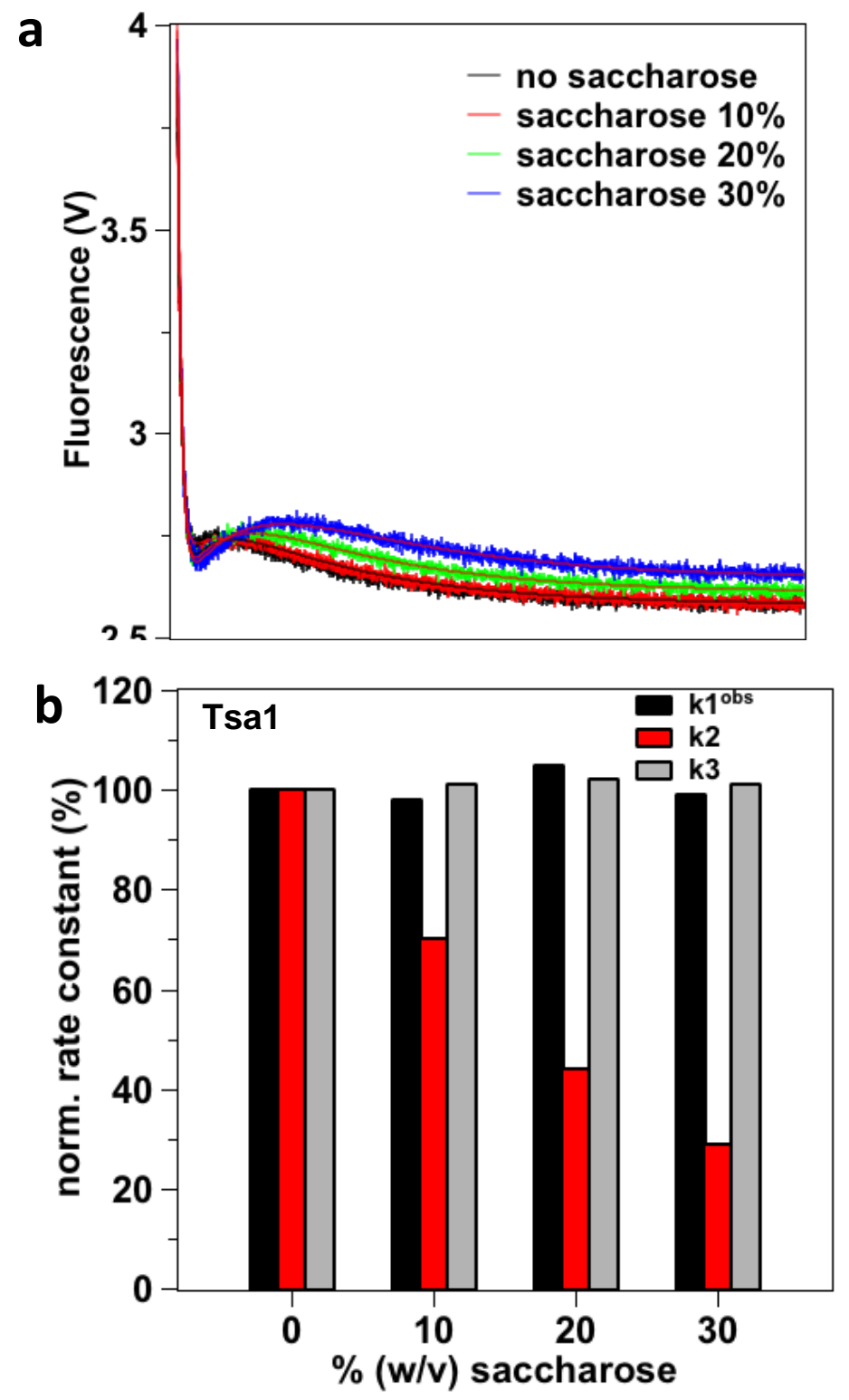

Figure S14. a, effect of saccharose ( $0 \%$ black, $10 \%$ red, $20 \%$ green and $30 \%$ blue) on the reaction of Tsa1 $(5 \mu \mathrm{M})$ with tBOOH $(10 \mu \mathrm{M})$ monitored as in Fig. 2b, fitted against a 3-exponential equation (red or black line). $b$, effect of saccharose concentration on rate constants $k 1^{\text {obs }}, k 2$ and $k 3$ normalized to $0 \%$ saccharose. 


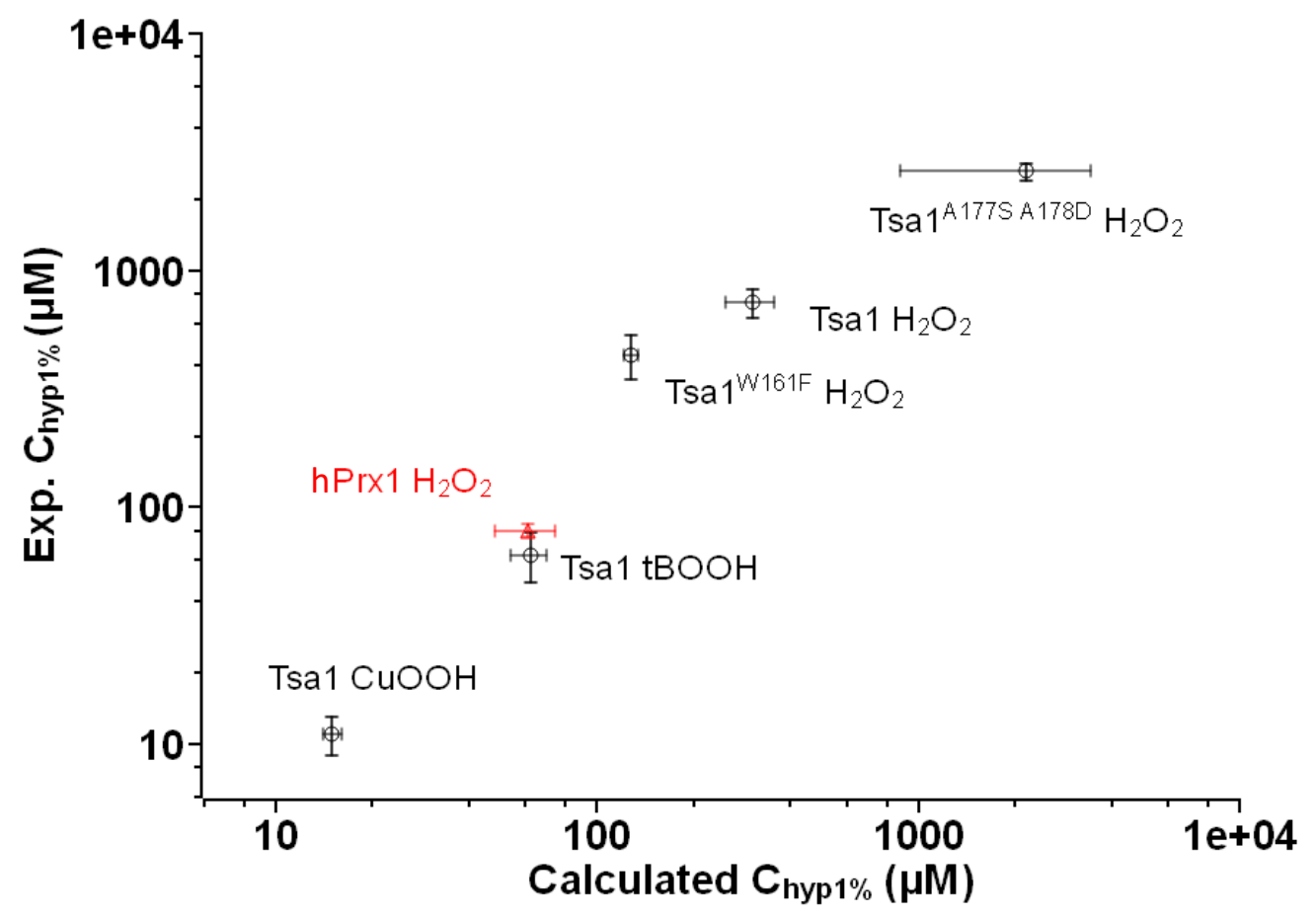

Figure S15. Comparison of the calculated and experimental $\mathrm{C}_{\mathrm{hyp} 1 \%}$ for wild-type and mutant Prxs 

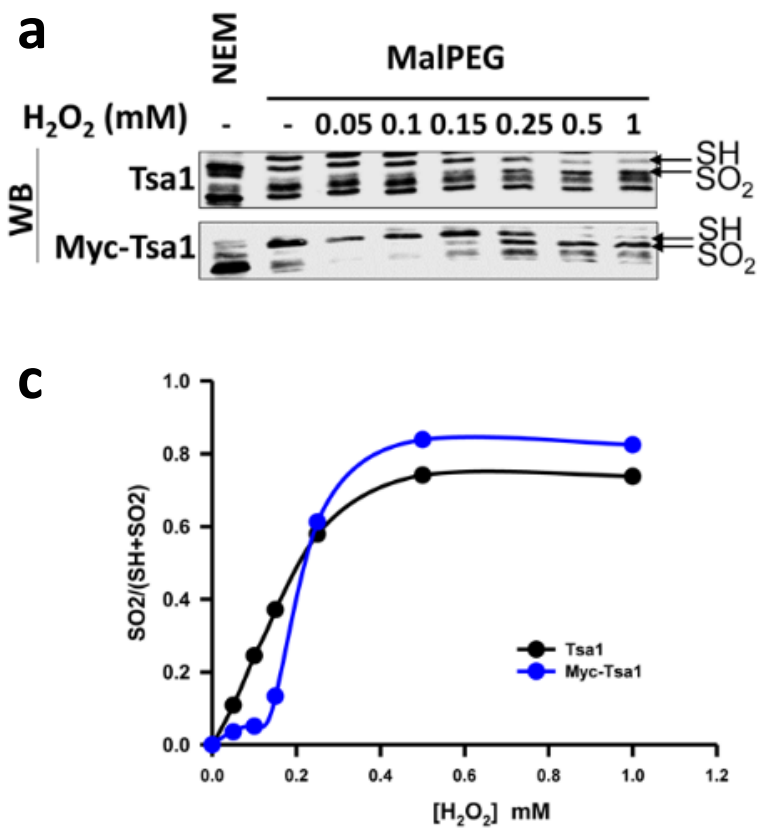

b MalPEG

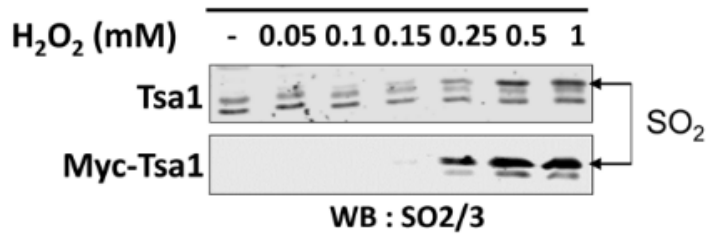

Figure S16. Validation of the mPEG differential cysteine derivatization procedure to monitor $\operatorname{Prx}$ hyperoxidation using $\mathrm{N}$-terminal tagged Tsa1 (Myc-Tsa1), and comparison of the reactivity of Myc-Tsa1 and Tsa1 towards $\mathrm{H}_{2} \mathrm{O}_{2}$. a,b, Thiols were derivatized by NEM or mPEG, as indicated, after reduction with DTT, as described in methods, using cell lysates of $\Delta t s a 1$ expressing human Tsa1 or Myc-Tsa1 and exposed to $\mathrm{H}_{2} \mathrm{O}_{2}$ at the indicated concentration. a, Western blot of reduced (-SH) (2 X mPEG) and hyperoxidized $\left(-\mathrm{SO}_{2} \mathrm{H}\right)(1 \mathrm{X}$ mPEG) forms of Tsa1 and Myc-Tsa1 (indicated by black arrows), revealed with an anti-Prx (Tsa1) or anti-Myc (Myc-Tsa1) antibody. Quantification of the degree of oxidation $\left(\mathrm{SO}_{2} \mathrm{H} / \mathrm{SH}+\mathrm{SO}_{2} \mathrm{H}\right)$ is shown below the western blot $(c)$. $b$, Western blot of the $\mathrm{SO}_{2} \mathrm{H}$ forms of Tsa1 and Myc-Tsa1, using a Prx anti-SO $\mathrm{SO}_{2 / 3}$ antibody and the cell lysates used in a. 